\title{
A IMPORTÂNCIA DA INTENSIFICAÇÃO DE PROCESSOS PARA A INDÚSTRIA QUÍMICA, UMA DISCUSSÃO EXPLORATÓRIA
}

\author{
R. A. S. da ROCHA ${ }^{1}$ e S. A. FILHO ${ }^{1}$ \\ ${ }^{1}$ Universidade Federal da Bahia, Departamento de Engenharia Química \\ E-mail para contato: raissaadriele@hotmail.com
}

\begin{abstract}
RESUMO - As necessidades de reduzir emissão de $\mathrm{CO}_{2}$ para a atmosfera são elevadas levando em conta a expectativa de crescimentos dos países em desenvolvimento. Segundo Agência Internacional de Energia e Painel Intergovernamental em Mudança de Clima(IPCC) será necessário reduzir 48 gigatonelada/ano para 2050. Não é uma missão impossível se trabalhada de forma estratégica, separando em dois blocos de ações, reduzir as emissões em instalações atuais, e projetar instalações futuras com integração e intensificação dos processos. Entende-se como intensificação de processos, a miniaturização de operações unitárias e processos, ou união de processos em um equipamento tornando-o mais compacto com as mesmas capacidades de produção, desta forma serão mais simplificados. Os custos operacionais diminuirão consideravelmente, aumentando a segurança da planta, diminuindo os resíduos, reduzindo os gastos de energia e água. Para isso, é necessário um aprimoramento dos fenômenos alvo em cada operação, aumentando as taxas de transporte, dando a cada molécula a mesma capacidade de transformação, maximizando a eficácia de eventos moleculares, ou seja, melhorando as forças motrizes e superando as limitações de cada processo. O desafio aliado a essa inovação é enorme, pois existem barreiras para implantação, como confiabilidade em tecnologias maduras, riscos devido à falta de precedente, falta de conhecimento sobre como e onde intensificar, e falta de unidades de intensificação de processos validadas. Por isso, a importância de estudar e entender intensificação.
\end{abstract}

\section{INTRODUÇÃO}

Em alguns lugares do mundo, os efeitos da emissão de $\mathrm{CO}_{2}$ e outros resíduos, devido a falta de preocupação das empresas com uma produção mais limpa, começam a aparecer e castigar a vida das pessoas, exemplos disso são a falta de água em São Paulo, as mudanças climáticas e aumento de temperatura. Rockström et al.(2009) fala sobre outras possíveis consequências dessas emissões, como, acidificação dos oceanos, destruição do ozônio estratosférico, interferências no ciclo global do fósforo e nitrogênio, perda da biodiversidade, poluição química, etc.

Outro aspecto importante é a tecnologia arcaica que ainda existe nas empresas, é hora de revolucionar a indústria criando novos equipamentos, melhorando os processos com novos métodos. Por isso, segundo Ávila et al. (2011) intensificar processos será uma solução após a 
recuperação de energias perdidas nas unidades operacionais atuais (ações previstas até 2050), para atender o cenário construído pela AIE quanto a emissão de GEE.

A intensificação de processos promete reduzir exageradamente o tamanho de equipamentos e aumentar significativamente a eficiência. Ou seja, é a miniaturização de operações unitárias e processos, o equipamento maior se torna compacto, mantendo a capacidade, melhorando rendimento, reduzindo os custos de manutenção da planta, aumentando a controlabilidade e segurança, reduzindo também os gastos de água e energia que são as utilidades mais usadas no processo, além de serem as que mais precisamos para sobreviver e que devem ser economizadas.

Para isso é necessário estudar os operações unitárias de forma a melhorar o fenômeno utilizado nelas, aprimorando o jeito de transformação das moléculas existente no processo, fazendo com que elas possam ter a mesma força de mutabilidade, superando as dificuldades que impedem o êxito total de um determinado processo. Sendo assim, é necessário que as barreiras existentes possam ser superadas e as empresas tomem consciência que essa mudança é extremamente importante.

\section{INTENSIFICAÇÃO DE PROCESSO: UM NOVO CONCEITO}

Segundo Gani et al. (2010), intensificar processos proporciona oportunidades e desafios para muitos atributos como, aumento da produtividade, aumento da capacidade, maior segurança, maior flexibilidade, diminuição da energia usada e de resíduos. Isso pode ser alcançado por adição/reforço de fenômenos em um processo através da integração de operações, funções ou, alternativamente, através do reforço orientado do fenômeno numa operação. Por exemplo, em uma reação, aumentando a capacidade de transformação das moléculas, o número de choque efetivos também aumenta, fazendo com que o rendimento seja consideravelmente maior, quase chegando a $100 \%$.

Há alguns princípios que são associados a intensificação de processos e que são a base para alcançar o objetivo discutido, ou seja, é essencial realizá-los mesmo que não todos mas pelo menos um ou mais combinados, eles são, integração das operações, integração de funções, inserção de fenômenos e/ou aprimoramento alvo de um fenômeno numa dada operação. No caso de integrar operações, em um processo que há destilação e reação, podemos criar um equipamento que possua duas funções, sendo assim uma destilação reativa, seguindo essa análise pode ser projetado reator membrana que é um reator de fluxo continuo, que tem a função de separar e catalisar, além de outros exemplos como separação reativa, reator de disco giratório, etc. Dessa forma será possível reduzir os espaços, melhorando o desempenho das funções.

Essa abordagem é integralizada por Gani et al. (2012), unindo a visão de vários autores ele mostra que são necessários muitos estudos, devido a complexidade do assunto, mas também nos diz que devemos ir a fundo nessa questão porque nos prova que é possível trazer melhorias surpreendentes, possibilita um conhecimento maior sobre todo o processo, dentro disso teremos a oportunidade de controlar e observar um volume de controle menor no interior do processo, eliminando alguns 'erros' que façam com que a produção seja menor ou que impeçam que o processo atinja o máximo de rendimento executável. 
Inovações tecnológicas, como essa, podem passar por dificuldades e precisam superar diversas barreiras até serem desenvolvidas, como, falta de confiança por parte dos investidores, falta de unidades de intensificação validadas, ausência de critérios para avaliação do processo intensificado, alto custo nas instalações. Estes obstáculos devem ser ultrapassados, pois através desse tipo de implantação podemos mudar o mundo trazendo mais sustentabilidade, segurança e controle para a indústria.

Existem muitas opções e formas de intensificar um processo, como mostrado na Figura 1, mas o que ainda não existe é uma metodologia sistemática que possibilite a escolha dos equipamentos, alguns passos são propostos por alguns autores para chegar a opção que se encaixa melhor para atingir o objetivo requerido, por isso a importância de discutir e pesquisar, a partir daí já surgem maiores probabilidades da implantação obter sucesso, além de diminuir as tentativas, esse pode ser o caminho para o começo de uma transformação na Engenharia Química.

Figura 1- Opções de equipamentos e métodos para intensificação de processos.

Fonte: Adaptada de Ramshaw et al. (2008).

\section{Processos de intensificação}

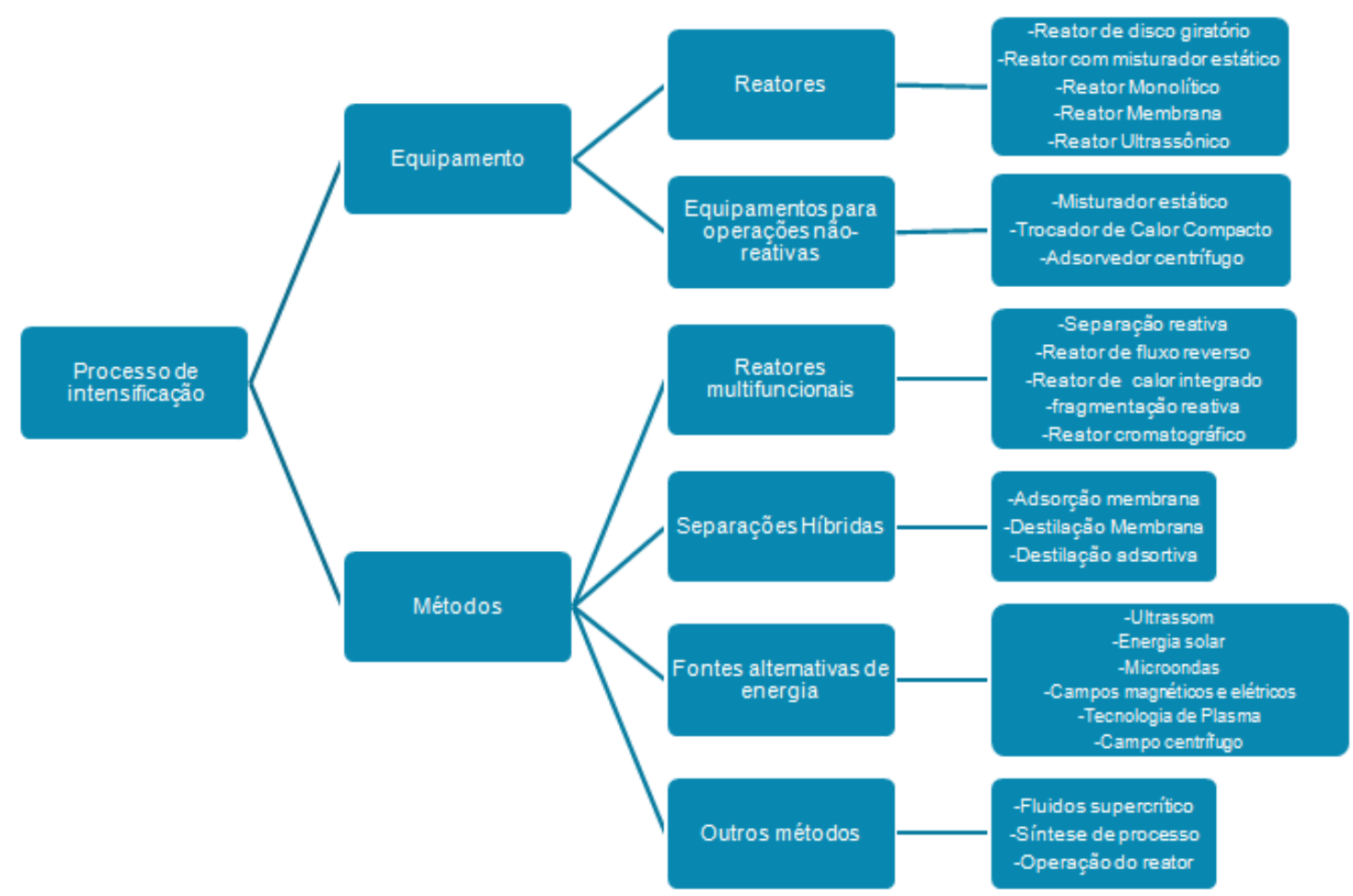

\section{UMA VISÃO DO FUTURO}

A intensificação de processos permite unir dois ou mais equipamentos e/ou processos em um só, essa combinação de processos terá um papel importante para um futuro sustentável e para uma produção mais limpa. Com toda essa evolução, Stankiewicz (2000) fala sobre a 
ideia de que as operações unitárias tradicionais serão extintas dando lugar aos projetos modulares que emergem após a intensificação, mas isso não acontecerá assim, pois as técnicas e os conhecimentos oriundos dessas operações são o alicerce de todo projeto do processo. As operações unitárias continuarão existindo o que mudará serão os dispositivos e métodos utilizados para que elas sejam executadas.

É provável que daqui a alguns anos, uma planta inteira seja bastante reduzida e caiba em um galpão, devido ao acoplamento dos equipamentos, é possível ter uma ideia do que seria uma planta intensificada na figura 2. Através dessa imagem, percebemos a grandeza de intensificar um processo. Galiana (2010) diz que evidências mostram que a humanidade está mudando o balanço energético da Terra, a mudança no equilíbrio de energia é atribuível à acumulação na atmosfera de gases com efeito de estufa. Com todos os problemas socioambientais, como aumento de temperatura e falta de água, devido aos impactos ambientais que algumas indústrias causam, vemos na intensificação de processos a esperança de um meio ambiente mais saudável, vemos uma solução para o futuro devastador que está por vim se não mudarmos as atitudes e ações.

Figura 2 - Previsão do futuro: Plantas atuais (à esquerda) e Plantas após a intensificação dos processos (à direita). Fonte: Stankiewicz (2000).

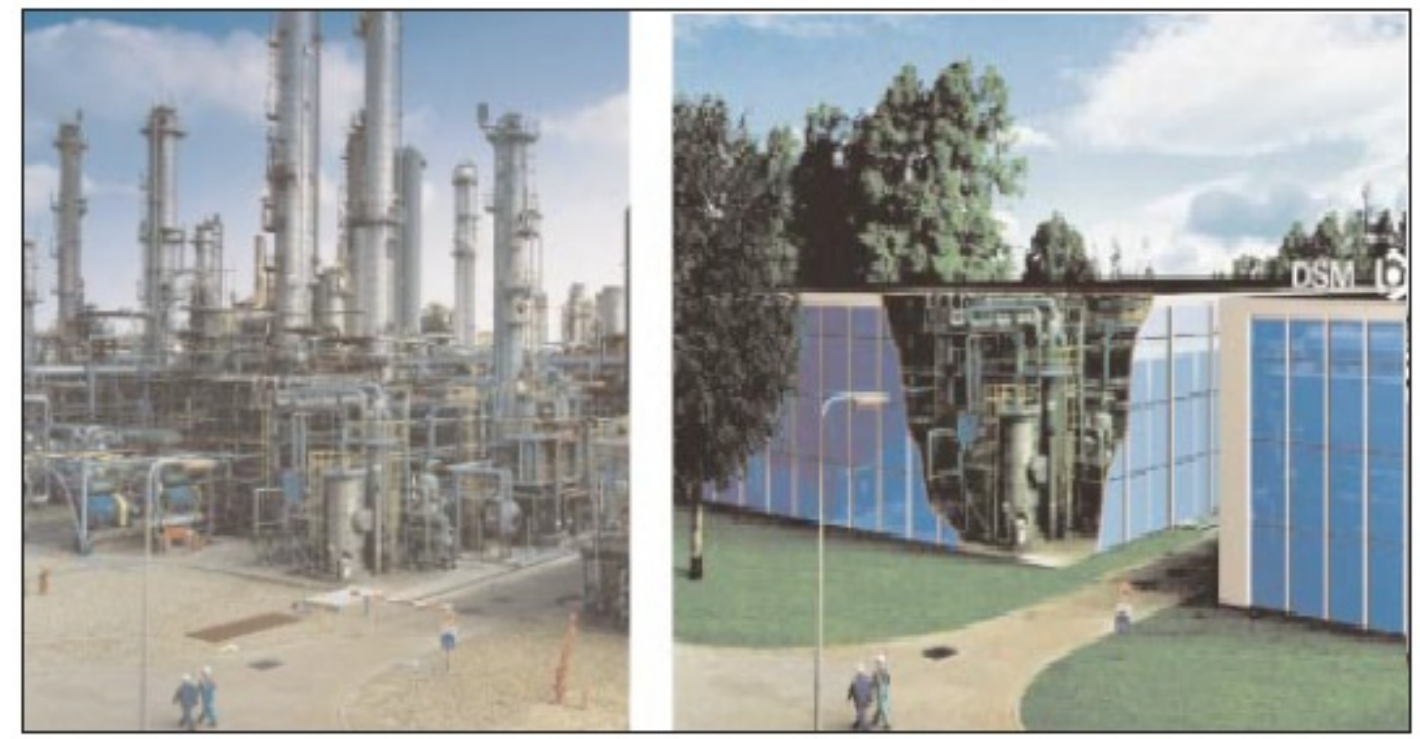

\section{CONCLUSÃO}

Diante dos danos que já foram causados, dos que estarão por vim se não houver mudanças na indústria, das tecnologias ultrapassadas que ainda são utilizadas, da imprecisão dos projetos feitos (colocando na planta uma capacidade superior para garantir a capacidade requerida), do demasiado gasto de água e energia, da alto volume de resíduos gerados pelas empresas; vimos a importância da transformação que a indústria deve passar. Podemos perceber os grandes benefícios que a intensificação de processos poderá trazer para as plantas químicas. 
Além de reduzir o gasto das utilidades e resíduos, as plantas serão mais compactas, gerando a possibilidade de um maior controle sobre o sistema, garantindo o que o processo atinja sucesso pleno. Isso significa mais lucro para empresa bem como mais proteção ao meio ambiente. Vimos também que ainda é necessário mais investimentos para pesquisas sobre o assunto, é essencial que haja uma planta piloto no Brasil para a realização de testes, por ser um tema novo ainda há um pouco de insegurança por parte das indústrias, por isso a construção de equipamentos intensificados traria mais confiabilidade para este estudo.

\section{NOMENCLATURA}

AIE - Agência Internacional de Energia

Gta - Gigatonelada/ano

GEE - Gases do efeito estufa

IPCC - Intergovernmental Panel on Climate Change

\section{REFERÊNCIAS}

ÁVILA, S.; KIPERSTOK, A.; BRAGA, B.; KALID, R. Avoiding loss of energy in a petrochemical industry, operation and design. Conference proceedings issue: 057 . v. 7, p. 1552-1559, 2011

GANI, R.; LUTZE, P.; WOODLEY, J. M. Process intensification: A perspective on process synthesis. Elsevier., v. 49, p. 547-558, 2010.

GANI, R.; LUTZE, P.; ROMÁN-MARTINEZ, A.; WOODLEY, J. M. , A systematic synthesis and design methodology to achieve process intensification in (bio) chemical processes. Elsevier. v. 36, p. 189-207, 2012.

ROCKSTRÖM, J.; STEFFEN, W.; NOONE, K. et al. Planetary Boundaries: Exploring the safe operating space for humanity. Ecology and Society, in press $14^{\text {th }}$ september, 2009.

STANKIEWICZ, A. I.; MOULIJN, J. A. Process Intensification: Transforming Chemical Engineering, Chemical Engineering Progress, Process Design Trends, p. 22-33, 2000.

GALIANA, I.; GREEN, C. An Analysis of a Technology-Ied Climate Policy as a Response to Climate Change. Copenhagen Consensus On Climate. Frederiksberg, Denmark, 2000.

RAMSHAW, C.; REAY, D.; HARVEY, A. Process Intensification: Engineering for Efficiency, Sustainability and Flexibility. Burlington, USA: Editora ButterworthHeinemann, 2008. 